\title{
ADVANCES IN DILUTE NITRIDE MULTI-JUNCTION SOLAR CELLS FOR SPACE POWER APPLICATIONS
}

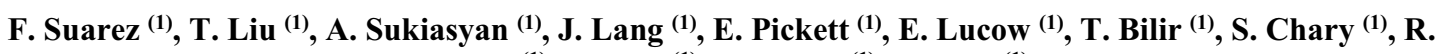 \\ Roucka $^{(1)}$, I. Aeby $^{(1)}$, L. Zhang ${ }^{(1)}$, S. Siala ${ }^{(1)}$ \\ (1) Solar Junction Corp., 401 Charcot Avenue, San Jose, CA 95131 U.S.A, Email: fsuarez@sj-solar.com
}

\begin{abstract}
A sub-cell with bandgap of around $1 \mathrm{eV}$ is required to improve the efficiency of multi-junction solar cells beyond what is possible with legacy triple-junction architectures [1]. Solar Junction Corporation has been focused since 2007 on the development and commercialization of dilute nitride materials to be used as the $1 \mathrm{eV}$ sub-cell in a fully lattice matched multijunction solar cell. Initial focus on the terrestrial concentrating photovoltaics (CPV) market led to Solar Junction Corp.'s achievement of multiple world records in multi-junction solar cell efficiency with its triplejunction cells on GaAs [2], [3]. These solar cells have been available as commercial products since 2010. Solar Junction Corp. has leveraged its high-quality, manufacturable dilute nitride material to develop and introduce an entirely new class of space solar cells capable of reaching over $33 \%$ AM0 conversion efficiency in a four-junction (4J) configuration lattice matched to active Ge substrates, with a clear line of sight to $36 \%$ AM0 efficiency in five- or six-junction devices that can be manufactured more cost-effectively than devices relying on metamorphic technologies.
\end{abstract}

In this paper, we review the latest performance and qualification results of Solar Junction Corp.'s lattice matched 4J-on-Ge space solar cells and CIC (CellInterconnect-Coverglass) products incorporating GaInNAsSb dilute nitride material. We also report on the production readiness of these advanced space solar cells manufactured using an optimized hybrid Molecular Beam Epitaxy (MBE) / Metal Organic Vapor Phase Epitaxy (MOVPE) growth process.

\section{INTRODUCTION}

Within the multi-junction solar cell industry, it has long been known that to improve efficiency beyond what is possible with existing triple-junction solar cells, there needs to be a material that can provide a $1 \mathrm{eV}$ bandgap. GaInNAsSb, a material variant historically referred to as 'dilute nitride,' is the only known material that absorbs in the IR and is lattice-matched to other materials used in multi-junction solar cells [4], [5]. By adjusting the amount of nitrogen and indium in GaInNAsSb, the lattice constant remains matched to GaAs and germanium, thereby preserving the existing reliability paradigm of lattice-matched compound semiconductor structures while enabling the bandgap to be tuned from $0.8 \mathrm{eV}$ to
$1.4 \mathrm{eV}$, as shown in Fig 1.

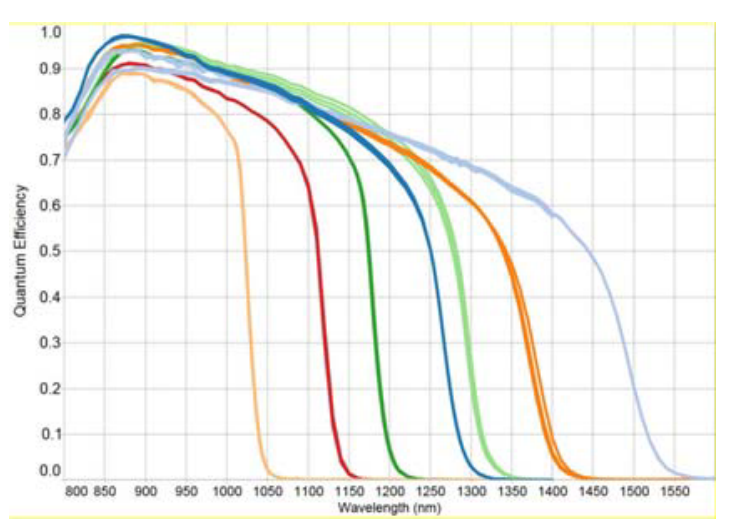

Figure 1. Band gap tunability characteristics of Solar Junction's Dilute Nitride material.

Developing high quality dilute nitride material for a $1 \mathrm{eV}$ sub-cell proved to be challenging despite substantial investment and development efforts by numerous industrial and research groups over many years. Solar Junction Corp. has taken a leadership role in improving the dilute nitride material (e.g. the use of $\mathrm{Sb}$ as a surfactant). These efforts have resulted in record efficiencies achieved in GaInNAsSb-containing triple junction (3J) solar cells [2], [3] and enabled Solar Junction Corp. to develop an extensive U.S. and international patent portfolio covering dilute nitride materials for solar cells.

Initially developed to meet the needs of terrestrial CPV systems, Solar Junction Corp.'s high-reliability latticematched solar cell technology has now been adapted for use in the AM0 illumination condition of space. This technology forms the foundation for Solar Junction Corp.'s multi-generational efficiency roadmap, depicted in Fig. 2, which is expected to enable the development and production of devices exceeding 36\% AM0 conversion efficiency.

Lattice matched 3J space cells on GaAs with $31 \%$ conversion efficiency have already been developed [6]. Solar Junction Corp.'s 3J dilute nitride cells have been operating in low earth orbit on two picosats launched in June 2014 by The Aerospace Corporation, and have shown excellent on-orbit performance, with equivalent or superior degradation factors when compared to conventional space qualified $\mathrm{InGaP} / \mathrm{InGaAs} / \mathrm{Ge} 3 \mathrm{~J}$ cells. 


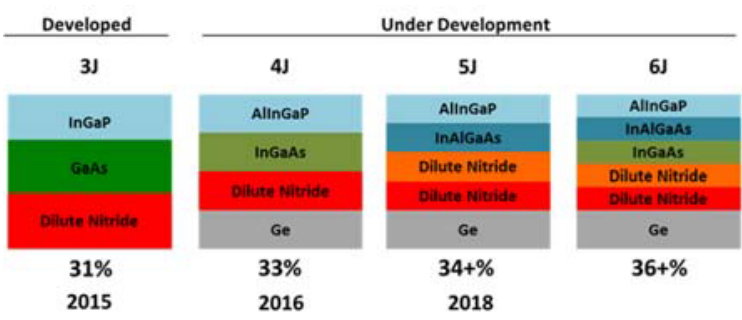

Figure 2. Solar Junction Corp. multi-junction space solar cell roadmap.

Fig. 3 shows the baseline and on-orbit Current vs. Voltage of these 3J dilute nitride solar cells [7].

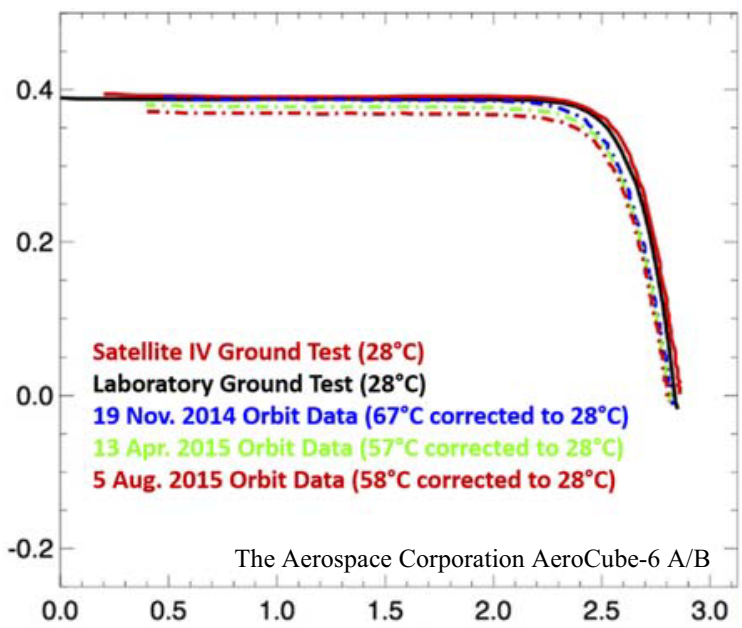

Figure 3. Change in I-V of $3 J$ dilute nitride space cells in low-earth orbit since June 2014 [7] (Courtesy of The Aerospace Corporation)

\section{4J Ge SPACE SOLAR CELLS}

A $4 \mathrm{~J}$ space solar cell product incorporating an upright growth, lattice matched dilute nitride structure on heritage Ge substrates is currently under development with a target conversion efficiency of $33 \%$ AM0 by the end of this year. The structure of the $4 \mathrm{~J}$ device is shown (inset) in Fig. 4.

Recently, Solar Junction Corp. successfully developed and demonstrated prototype $4 \mathrm{~J}$ cells with $33 \%$ AM0 conversion efficiency. Electrical performance characteristics of the prototype $4 \mathrm{~J}$ dilute nitride solar cell are shown in Fig. 3. To the best of our knowledge, this is the highest AM0 efficiency ever recorded in a latticematched solar cell. Current density versus voltage of a prototype cell with AM0 conversion efficiency of $33 \%$ is shown in Fig. 4(b) and its corresponding quantum efficiency is as shown in Fig. 5.

Preliminary stress testing of $4 \mathrm{~J}$ lattice matched solar cells has confirmed the reliability and robustness of this design. Cells subjected to humidity exposure at $45^{\circ} \mathrm{C}$, $95 \% \mathrm{RH}$, for 1000 hours remained stable.

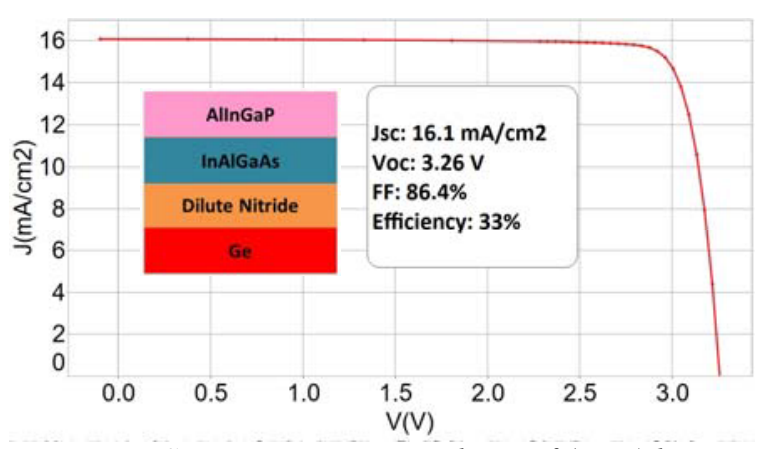

Figure 4. Current Density vs. Voltage of (inset) lattice matched $4 J$ on Ge space cell.

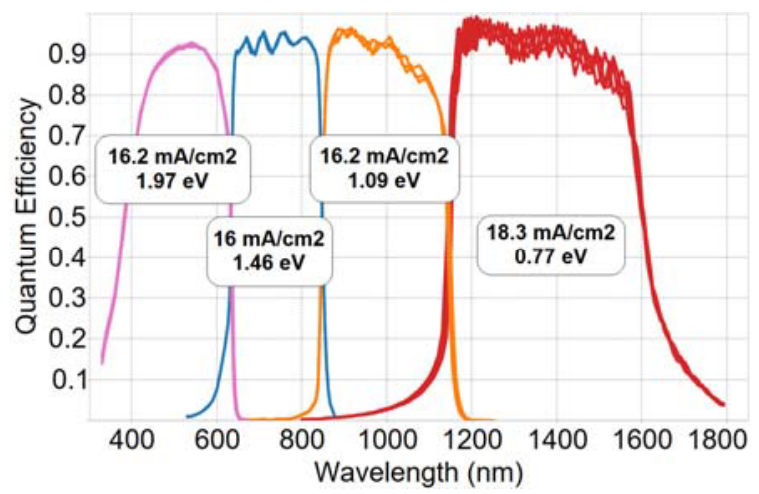

Figure 5. Quantum efficiency of lattice matched $4 \mathrm{~J}$ on Ge incorporating dilute nitride junction.

Additionally, these $4 \mathrm{~J}$ cells have performed well under irradiation and temperature annealing tests per ECSS-EST-20-08C. Proton irradiation effects were evaluated on sample 4J cells and the results show similar degradation to present generation space qualified $\mathrm{InGaP} / \mathrm{InGaAs} / \mathrm{Ge}$ triple junction solar cells. The results of these proton radiation effects tests are shown in Fig. 6 and Fig. 7. An end-of-life (EOL) design is planned to further enhance the radiation performance of these $4 \mathrm{~J}$ cells.

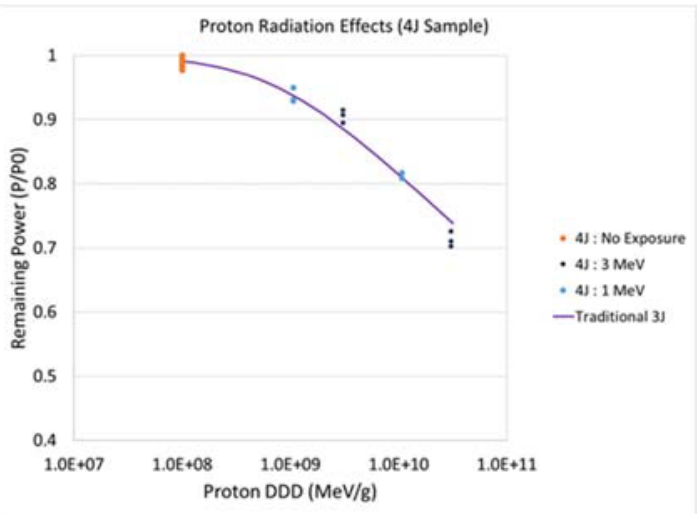

Figure 6. Remaining Power (P/Po) vs. Proton Displacement Damage of lattice matched $4 J$ on Ge cell. 


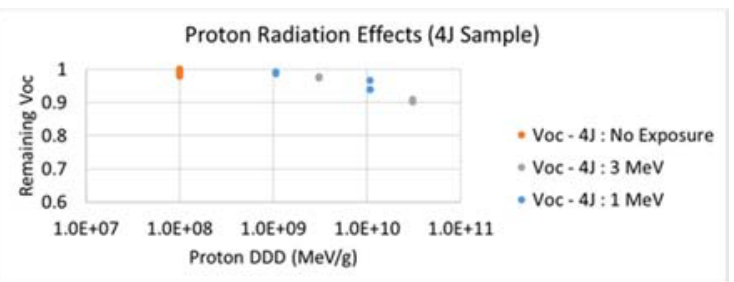

(a)

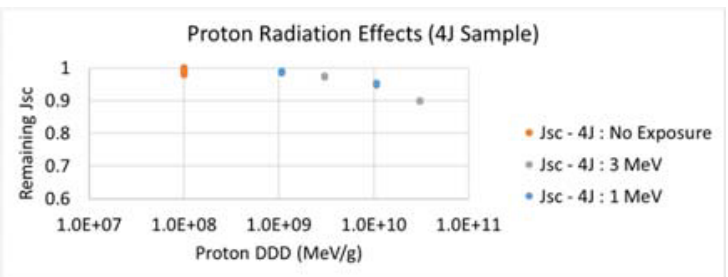

(b)

Figure 7. Remaining Voc (a) and Jsc (b) vs. Displacement Damage from 1 and $3 \mathrm{MeV}$ protons for lattice matched $4 J$ on Ge space cell.

\section{MANUFACTURING OF LATTICE MATCHED 4J SPACE CELLS}

The improved solar cell efficiency provided by the lattice matched GaInNAsSb material system is realized using a proven, cost effective, and relatively simple epitaxy manufacturing process that is consistent with the production of present generation space solar cells. Incorporating Solar Junction Corp.'s lattice matched GaInNAsSb material does not require increased thickness of the material stack to accommodate defect suppression layers, nor does it require additional capital assets for complex operations such as epitaxial release and substrate re-bonding. The hybrid MBE/MOVPE growth employed in creating the $4 \mathrm{~J}$ epitaxial structure leverages the advantages of both growth techniques and allows for optimal cost and performance for the epitaxial wafers. Additionally, uniform epitaxy is achieved consistently, enabling high performance large area solar cells such as the legacy $30 \mathrm{~cm}^{2}$ '2-per' (see Fig. 8) and $59.5 \mathrm{~cm}^{2}$ '1-per' form factors produced on $100 \mathrm{~mm}$ diameter wafers.

Solar Junction Corp.'s lattice matched 4J on Ge space solar cells provide a drop-in replacement for heritage $3 \mathrm{~J}$ cells with similar mechanical and thermal characteristics, making it possible to leverage existing integration equipment and heritage materials and processes for the manufacture of the cell and the integration of the cell into a CIC device.

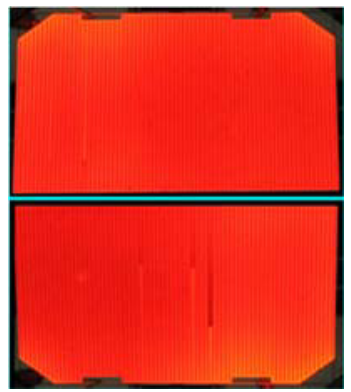

Figure 8. Electroluminescence of 2-per $4 J$ space cells.

\section{SUMMARY}

Building on Solar Junction Corp.'s breakthrough development of $3 \mathrm{~J}$-on-GaAs solar cells incorporating lattice matched GaInNAsSb dilute nitride material for the CPV market, we now report the development and demonstration of lattice matched, dilute nitride-based 4Jon-Ge space solar cells achieving 33\% AM0 conversion efficiency. Solar Junction Corp. is currently developing its CIC assembly capabilities and performing space qualification testing for its $4 \mathrm{~J}$ product, with commercial production of this new generation of space solar cell planned for 2017.

\section{REFERENCES}

1. Friedman, D.J., Geisz, J.F., Kurtz, S.R. \& Olson, J.M. (1998). 1-eV Solar Cells with GaInNAs Active Layer. J. of Crystal Growth 195, (1-4), pp409-415.

2. Wiemer, M, Sabnis, V \& Yuen, H. (2011). 43.5\% Efficient Lattice Matched Solar Cells. in Proc. of SPIE, 810804-5.

3. Jones-Albertus, R., et al. (2013). Pushing Solar Cell Efficiencies Even Higher. CLEO - Applications and Technology, San Jose, California, USA.

4. Kondow, M, et al. (1996) Jpn. J. Appl. Phys. (35), pp11273-75

5. Kurtz, S.R., Allerman, A.A., Jones, E.D., Gee, J.M. Banas, J.J. \& Hammons, B.E. (1999) "InGaAsN Solar Cells with $1.0 \mathrm{eV}$ Band Gap, Lattice Matched to GaAs", Appl. Phys. Lett. 74 (5), pp729-731.

6. Suarez, F. et al. (2015). Presentation at the 33rd Annual Space Power Workshop, Manhattan Beach, California, USA.

7. Liu, S., et al. (2015). Presentation at the 33rd Annual Space Power Workshop, Manhattan Beach, California, USA. 